\title{
Frequency of Nerve Root Sleeve Cysts in Autosomal Dominant Polycystic Kidney Disease
}

\author{
Murat Aşık ${ }^{1}$, Fatih Tufan², Timur Selçuk Akpınar ${ }^{2}$, Nilgül Akalın², Elvan Ceyhan ${ }^{4}$, Necmeddin Tunç $^{1}$, \\ Zehra Işık Hasıloğlu', Mehmet Rıza Altıparmak², Tevfik Ecder², Sait Albayram ${ }^{1}$
}

\footnotetext{
${ }^{1}$ Department of Radiology, İstanbul University Cerrahpaşa School of Medicine, İstanbul, Turkey ${ }^{2}$ Department of Internal Medicine, İstanbul University İstanbul School of Medicine, İstanbul, Turkey ${ }^{3}$ Department of Internal Medicine, İstanbul University Cerrahpaşa School of Medicine, İstanbul, Turkey ${ }^{4}$ Department of Mathematics, Koç University, İstanbul, Turkey
}

Background: There is sporadic data about the occurrence of spinal meningeal cysts in patients with autosomal dominant polycystic kidney disease (ADPKD). We suggest that there is a relationship with the frequency and size of spinal meningeal cysts and headache, intracranial aneurysms, and cerebrospinal fluid leakage in patients with ADPKD.

Aim: To investigate the relationship with spinal meningeal cyst, cerebrospinal fluid leakage, and headache in patients with ADPKD.

Study Design: Cross-sectional study.

Methods: We enrolled 50 patients with ADPKD and 37 healthy volunteers. This cross-sectional study included patients with ADPKD and matched healthy volunteers. Magnetic resonance imaging myelography was performed using the 3D-T2 HASTE technique in an MRI scanner. We questioned our subjects regarding presence of headache and evaluated headache severity using a visual analog scale. The relationship between the number and size of spinal men- ingeal cysts with headache, intracranial aneurysms, and liver cysts was also investigated.

Results: Spinal meningeal cysts were more numerous and larger in patients than in controls $(14.8 \pm 11.6$ vs. $6.4 \pm 4.6$ cysts respectively, $\mathrm{p}<0.001,68.3 \pm 49.3$ vs. $25.4 \pm 20.1 \mathrm{~mm}, \mathrm{p}<0.001$, respectively). Spinal cyst number and size were similar in APDKD patients with or without intracranial aneurysms. Headache score was correlated with the size and number of spinal meningeal cysts. This was valid only in patients with ADPKD.

Conclusion: Abnormality involving the vessel wall in ADPKD may explain the increased number of spinal meningeal cysts in ADPKD. Moreover, leakage of cerebrospinal fluid secondary to spinal meningeal cyst may be responsible for recurrent severe headache by causing spontaneous intracranial hypotension in these patients.

Keywords: Spinal meningeal cysts, autosomal dominant polycystic kidney disease, headache
Autosomal dominant polycystic kidney disease (ADPKD) is one of the most common hereditary kidney diseases with a frequency of $1 / 400$ to $1 / 1000$ (1). It is accepted as a systemic disease because cysts develop in the kidneys and other organs. Moreover, connective tissue disorders such as intracranial an- eurysms, arterial dolichoectasia, heart-valve abnormalities, and arterial dissections may be seen (1).

Spinal meningeal cysts (SMCs) have been reported in a case report and case series to be possible extrarenal findings of the disease $(2,3)$. SMCs are vesicles formed caused by abnormal

This study has been presented at the 48 ${ }^{\text {th }}$ Annual Meeting of American Society of Neuroradiology, 15-20 May 2010, Boston, MA, USA.

Address for Correspondence: Dr.Murat Aşık, Department of Radiology, İstanbul University Cerrahpaşa School of Medicine, İstanbul, Turkey

Phone: +905355553897 e-mail: muradyoloji@gmail.com

Received: 14 August $2015 \quad$ Accepted: 22 December $2015 \quad$ DOI: 10.5152/balkanmedj.2016.151093

Available at www.balkanmedicaljournal.org

Murat A, Fatih T, Selçuk AT, Nilgül A, Elvan C, Necmeddin T, et al. Frequency of nerve root sleeve cysts in autosomal dominant polycystic kidney disease.

Balkan Med J 2016;33:652-6. 
outgrowth from nerve sheaths of the arachnoid and dural sac and at the roots of spinal nerves. The etiology of the cysts is not yet fully understood (4). In time, cerebrospinal fluid (CSF) leaks develop from cysts in spinal meningeal regions in patients with ADKPD that may lead to spontaneous intracranial hypotension (SIH), which is deemed as an important cause of headache in these patients (5). Therefore, SIH may be an etiology of headache in patients with ADPKD, in addition to other causes like intracranial aneurysms.

\section{MATERIALS AND METHODS}

\section{Participants}

In the present study, we enrolled patients with ADPKD and healthy volunteers without any systemic diseases who applied to our department for extremity magnetic resonance imaging (MRI) because of trauma or pain. All patients gave written informed consent before MRI procedures. Exclusion criteria were any contraindications for MRI. The ethics committee of our institute approved this study.

\section{Study design}

In this cross-sectional study we divided the entire spinal region into three parts (cervical, thoracic, and lumbosacral), and a 1.5T MRI scanner (Symphony, Siemens; Erlangen, Germany) and 3D-T2 HASTE technique were used for MRI myelographic examinations (TR, $8000 \mathrm{~ms}$; TE $100 \mathrm{~ms}$; FOV, 250 ms; matrix size $256 \times 256$; thickness of cross-section $80 \mathrm{~mm}$ ). Two independent, experienced radiologists examined the images. Each of the spinal levels was examined bilaterally in terms of presence of SMCs and the numbers and sizes of cysts.

The presence and severity of headache in the patient and control groups was assessed by clinicians using visual analog scales. We asked the patients to score the intensity of their headaches from 0 to 10 points. Scores from 1 to 3 points were classified as mild headache, scores from 4 to 7 points were classified as moderate headache, and scores between 8 and 10 points were classified as severe headache. We performed timeof-flight MRI angiographic examinations in order to identify intracranial aneurysms.

\section{Statistical analysis}

We used statistical software R version 2.10.1 (R Foundation for Statistical Computing; Vienna, Austria) in our analyses. We expressed continuous data as mean \pm standard deviation and ordinal parameters as median (minimum-maximum) and used Fisher's exact and Pearson's Chi-square tests to compare
TABLE 1. Distribution of the regions according to the number of SMCs in patient group

\begin{tabular}{lccccc}
\hline & $<5 \mathrm{~mm}$ & $5-10 \mathrm{~mm}$ & $11-15 \mathrm{~mm}$ & $16-20 \mathrm{~mm}$ & Total \\
\hline Cervical & $124(15 \%)$ & $135(17 \%)$ & $11(1 \%)$ & & $270(33 \%)$ \\
Thoracic & $284(35 \%)$ & $84(10 \%)$ & $5(1 \%)$ & 1 & $374(46 \%)$ \\
Lumbo-sacral & $89(11 \%)$ & $68(8 \%)$ & $12(1 \%)$ & 4 & $173(21 \%)$ \\
Total & $497(61 \%)$ & $287(35 \%)$ & $28(3 \%)$ & $5(1 \%)$ & 817
\end{tabular}

TABLE 2. Distribution of the regions according to the number of SMCs in control group

\begin{tabular}{|c|c|c|c|c|}
\hline & $<5 \mathrm{~mm}$ & $5-10 \mathrm{~mm}$ & $11-15 \mathrm{~mm} \quad 16-20 \mathrm{~mm}$ & Total \\
\hline Cervical & $95(40 \%)$ & $46(20 \%)$ & & $141(60 \%)$ \\
\hline Thoracic & $34(14 \%)$ & $14(6 \%)$ & $2(1 \%)$ & $50(21 \%)$ \\
\hline Lumbo-sacral & $35(15 \%)$ & $8(3 \%)$ & 1 & $44(19 \%)$ \\
\hline Total & $164(70 \%)$ & $68(29 \%)$ & $3(1 \%)$ & 235 \\
\hline
\end{tabular}

categorical data. We used Student's t test to compare continuous variables and the Mann-Whitney $U$ test to compare ordinal variables. We performed correlation analyses with Pearson and Spearman correlation coefficients for continuous and ordinal variables as needed, and provided p-values for the null hypothesis of correlation being zero. We considered the strength of correlation when $r$ was $0.1-0.3$ as weak, $0.4-0.5$ as moderate, and $>0.5$ as strong. We considered the results significant when $\mathrm{p}$ values were less than 0.05 .

\section{RESULTS}

Fifty patients with ADPKD (21 men and 29 women) and 37 healthy volunteers (16 men and 21 women) were included. The age range was between 13 and 78 years (mean age $42.8 \pm 12.1$ years) in the patient group and between 14 and 78 years (mean age $44.2 \pm 13.3$ years) in the control group.

The number of SMCs was higher in patients with ADPKD than in the control group ( $14.8 \pm 11.6$ vs. $6.4 \pm 4.6$ cysts respectively, $p<0.001$, Table 1,2$)$. The sizes of the cysts were significantly larger in the patient group $(68.3 \pm 49.3$ vs. $25.4 \pm 20.1$ $\mathrm{mm}, \mathrm{p}<0.001)$. The region in which the participants had the most cysts was the right cervical 7 , with $32(64 \%)$ cysts in the ADPKD patients and $18(48.6 \%)$ cysts in the controls $(\mathrm{p}=0.15$, Figure $1 \mathrm{a}-\mathrm{d})$. The regions with the largest cysts in the ADPKD group were the right lumbar 3, right sacral 5, left lumbar 3 , and left sacral 5 , with the diameter of the cysts being $20,18,17$, and $17 \mathrm{~mm}$ respectively (Figure $2 \mathrm{a}-\mathrm{b}$ ). The regions with the largest cysts in the control group were the right sacral 5 , right thoracic 8 , and left thoracic 5 with the diameter of the cysts being 14,13 , and $12 \mathrm{~mm}$, respectively. The regions with 

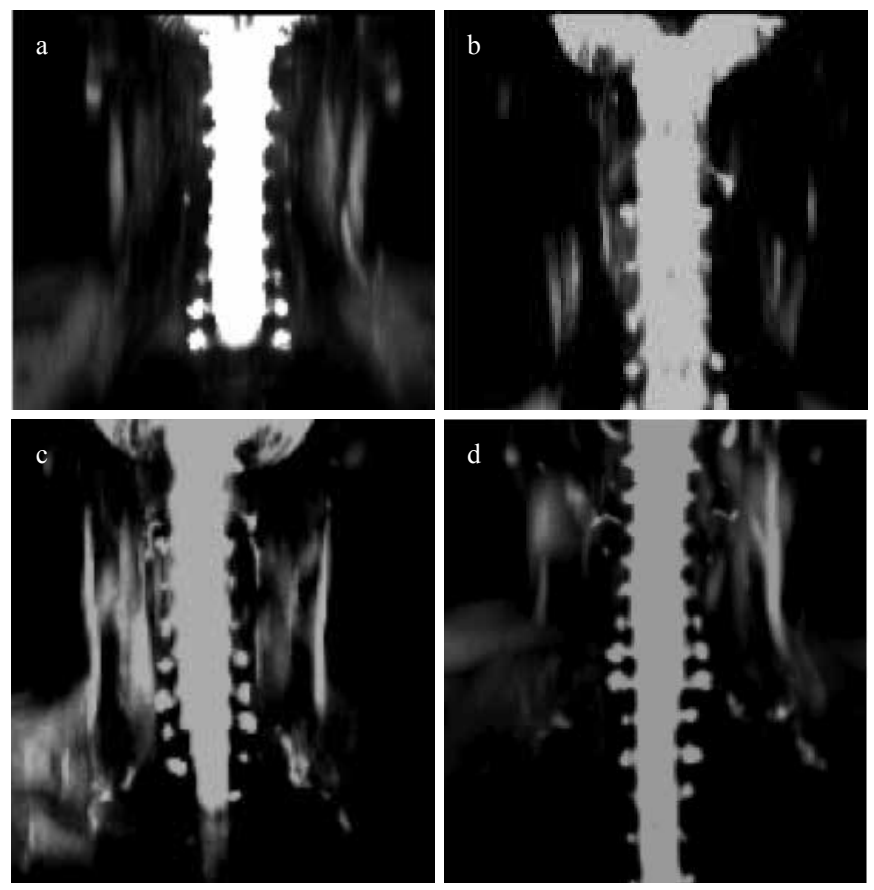

FIG. 1. a-d. T2W HASTE magnetic resonance myelographic images show bilateral cervical (a-b) and cervico-thoracic (c-d) spinal meningeal cysts.
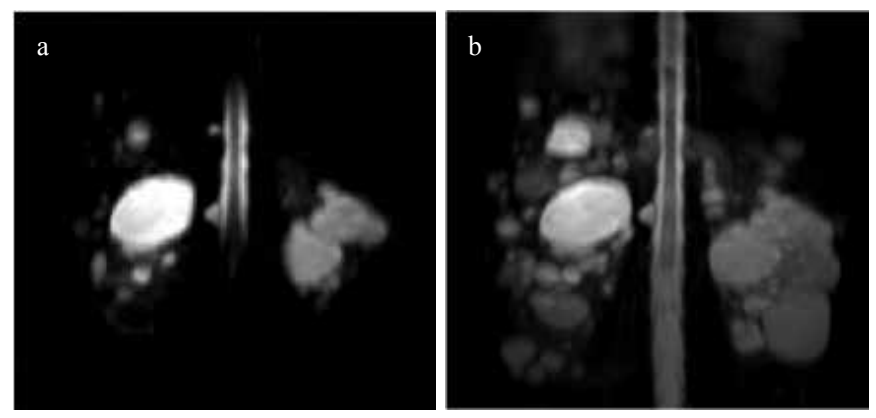

FIG. 2. a-b. T2W HASTE magnetic resonance myelographic images show unilateral right lumbar (a-b) spinal meningeal cysts and multiple cysts in both kidneys.

the most ADPKD patients having cysts were the right cervical 7 , left cervical 7, right cervical 8, and left cervical 8 , with 32 (64\%) having cysts in these regions. The regions where the most controls had cysts were the right cervical 6 , left cervical 6 , right cervical 7, and left cervical 7, with 24 (64.9\%), 20 (54.1\%), 18 (48.6\%), and 17 (45.9\%) controls having cysts in these regions, respectively.

The number and total size of SMCs was similar for both sexes within the two groups. The number and total size of right and left sided cysts were also similar in both sexes. This was valid for patients with ADPKD and controls.

Fourteen of the patients did not have a headache history, whereas 36 patients had mild, moderate or severe headaches. The headache score in females was higher than that in males in patient group ( $3.1 \pm 3.3$ vs. $1.4 \pm 2.5, \mathrm{p}=0.01)$. This finding was valid for female ADPKD patients compared with their male counterparts ( $4.8 \pm 3$ vs. $2.4 \pm 3.1, p=0.015)$; the female controls had similar headache scores to their male counterparts $(0.9 \pm 2.1$ vs. $0.3 \pm 0.6, \mathrm{p}=0.3)$.

In the patient group, intracranial aneurysm was detected in five female patients $(10 \%)$, three of whom had previously undergone interventions for aneurysms. ADPKD patients with and without aneurysms had similar SMC numbers $(15.4 \pm 4.3$ vs. $14.7 \pm 12.1$, $\mathrm{p}=0.9$ ) and total size ( $78 \pm 27$ vs. $67.2 \pm 51.3, \mathrm{p}=0.6)$. Headache scores of ADPKD patients were higher than those of controls (4 $(0-10)$ vs. $0(0-8), p<0.001)$. ADPKD patients with aneurysms tended to have higher headache scores compared with ADPKD patients without aneurysms $(8(0-10)$ vs. $3.5(0-10), \mathrm{p}=0.14)$. There was a moderate and positive correlation between headache score and the number $(r=0.47$ and $\mathrm{p}<0.001)$ and size $(r=0.52$ and $\mathrm{p}<0.001$ ) of cysts in patient group. Although there was a moderate and positive correlation between headache score and the number $(r=0.38$ and $\mathrm{p}=0.009)$ and size $(\mathrm{r}=0.39$ and $\mathrm{p}=0.007)$ of the cysts in the ADPKD group, there was a non-significant and weak correlation between headache score and total cyst size $(\mathrm{r}=0.18, \mathrm{p}=0.29)$, and no correlation between headache score and cyst number among controls $(\mathrm{r}=0.06, \mathrm{p}=0.7)$.

In the ADPKD group, the highest number of extrarenal cysts was in the liver ( 24 patients, 6 men and 18 women, had 1-9 cysts). Liver cysts were more commonly present in female ADPKD patients compared with male ADPKD patients $(62.1 \%$ vs. $28.6 \%, p=0.019)$. No liver cysts were detected in the control group. ADPKD patients with and without liver cysts had a similar age, headache score, total SMC number and size and similar aneurysm rates. There was no correlation between number of liver cysts and headache scores in the ADPKD group.

\section{DISCUSSION}

Autosomal dominant polycystic kidney disease is characterized by cysts in various organs and tissues, and collagen and extracellular matrix (ECM) anomalies $(6,7)$. ADPKD is the most common hereditary kidney disease with a frequency of $1 / 400$ to $1 / 1000$ live births. Cysts are also found in many extrarenal tissues such as liver, pancreas, spleen, testis, and arachnoid mater (1).

The mutations in polycystic kidney disease-1 (PKD-1) $(85 \%$ of the cases) and PKD-2 (15\% of the cases) genes are responsible for the disease $(8,9)$. As a result of mutation in these genes, proteins named polycystin- 1 and polycystin-2 that interact with each other in the cell membrane are synthesized. These proteins play an important role in cell-cell and cell-ECM communication, cell differentiation and synthesis of basal membrane. In 
patients with ADPKD, polycystin-1 protein is over-synthesized in the epithelial cells of kidney cysts, and has also been found in the gall-bladder, pancreas vessels and cerebrovascular structures. A disorder in collagen and ECM synthesis and metabolism leads to splitting and duplication of the basal membrane of epithelial cells and incompliance of ECM and development of cysts in patients with ADPKD. This compliance disorder explains the development of cysts in other organs, intracranial aneurysms, heart valve anomalies, and other extrarenal disorders, such as hernia and diverticula (10-12). The most common extrarenal finding in patients with ADPKD is liver cysts, with an incidence of up to $50 \%$ (13).

Cardiovascular findings include heart valve anomalies (the most common is mitral valve prolapsus with an incidence of $25 \%$, tricuspid valve proplapsus, aortic and tricuspid valve regurgitation), dilatation of the aortic root, dissection of the thoracic aorta and cervico-cephalic arteries, and coronary artery aneurysms $(8,12)$. It has been reported that aortic dissection is associated with collagen tissue defect in patients with ADPKD (14).

In our study, we found that patients with ADPKD had more and larger SMCs compared with the control group. The number and size of these cysts were associated with severity of headache solely in patients with ADPKD. The presence of intracranial aneurysms was not associated with the greater number and size of SMCs in patients with ADPKD. However, the presence of intracranial aneurysms tended to be associated with headache severity in the ADPKD group. Liver cysts did not seem to affect headache or SMC properties.

Autosomal dominant polycystic kidney disease patients suffer intracranial aneurysms with a frequency of approximately $12.4 \%$ and five times more frequently than the general population (15). It has been suggested that the cause of intracranial aneurysms in these patients is polycystin- 1 protein, which leads to the deterioration of the structure of vascular smooth muscle cells $(16,17)$. It has been determined that abnormal polycystin protein leads to arachnoid cysts in patients with ADPKD $(18,19)$. Although the frequency of arachnoid cysts is $1 \%$ in the general population, it is $8.1 \%$ in patients with ADPKD (20). Another recently discovered finding in patients with ADPKD is SMCs $(2,3,21,22)$. Albayram et al. (3) previously described a case of SIH associated with SMCs and dural leaks in a patient with Marfan syndrome and ADPKD. Schievink et al. (2) reported three cases of spinal meningeal diverticula that were incidentally detected as a result of intracranial aneurysm screening of 178 patients with ADPKD. Peces et al. (22) incidentally found sacral radicular cysts in a patient with ADPKD. Coche et al. (21) found seven thoracic SMCs in a patient with ADPKD. To our knowledge, there is no systematic study assessing the frequency of SMCs in patients with ADPKD. SMCs are vesicles caused by abnormal outward extensions of the dura mater, arachnoid mater, and nerve root sheath (4). The exact reason why SMCs are seen more frequently in these patients is not known. Because the arachnoid mater, dura mater and spinal nerve root sheaths are also composed of connective tissues, we suggest that abnormal polycystin protein may lead to deterioration in the structure of the ECM, leading to weakening of tissue integrity in meningeal structures. As a result of the effect of pulsatile CSF pressure, together with weakening in tissue integrity, dural ectasia, and eventually meningeal cysts and diverticula may develop. Nevertheless, the fact that spinal meningeal diverticula are also found in Marfan syndrome and connective tissue diseases such as neurofibromatosis supports the notion that the underlying cause may be weakness of the meningeal connective tissue $(2,21,23-27)$.

The presence and severity of headache were also evaluated in the current study. There are many factors that may lead to headache in patients with ADPKD that are encountered more frequently than in the general population. The most important factors include intracranial aneurysms, arachnoid cysts, and the resulting subdural bleeding. Spontaneous spinal CSF leak may result from weakness of spinal meningeal tissue and may lead to attacks of SIH (28). It was first suggested in 1994 that the underlying reason for spinal CSF leak might be systemic connective tissue diseases (29). In retrospective studies, patients with spontaneous spinal CSF leak were shown to have a very high frequency (16-36\%) of connective tissue diseases $(2,5,30)$. Considering the effects of ADPKD on the meningeal connective tissues, spontaneous CSF leaks may occur as a result of rupture of SMCs and lead to SIH in these patients (2).

Our study has certain limitations including its cross-sectional design, limited sample size and the absence of genetic analysis.

We suggest that the abnormality that involves the vessel wall in ADPKD may also affect the spinal dura. This may explain the increased number of SMCs in these patients. SMCs may be an extrarenal finding of ADPKD and their spontaneous rupture and leakage of cerebrospinal fluid may be responsible for the recurrent severe headache attacks in these patients. Further studies investigating the pathogenesis and clinical consequences of SMCs in these patients are warranted.

Ethics Committee Approval: Ethics committee approval was received for this study from the ethics committee of İstanbul University Cerrahpaşa School of Medicine.

Informed Consent: Written informed consent was obtained from patients who participated in this study.

Peer-review: Externally peer-reviewed.

Author contributions: Concept - S.A.; Design - M.A., S.A.; Supervision - S.A., M.A., Z.I.H.; Resource - M.A., N.T.; Materials - F.T., N.A., T.E.; Data Collection and/or Processing - E.C., M.A., S.A.; Analysis and/or Interpretation - E.C., M.A., S.A.; Literature 
Search - M.A., S.A.; Writing - M.A., F.T., T.S., N.A.; Critical Reviews - M.A., F.T., N.A., S.A., T.E.

Conflict of Interest: No conflict of interest was declared by the authors.

Financial Disclosure: The authors declared that this study has received no financial support.

\section{REFERENCES}

1. Ecder T F-BG, Schrier RW. Polycystic kidney disease. In: Schrier RW, ed. Diseases of the kidney and urinary tract. Philadelphia: Williams \& Wilkins; 2007:502-39.

2. Schievink WI, Torres VE. Spinal meningeal diverticula in autosomal dominant polycystic kidney disease. Lancet 1997;349:1223-4. [CrossRef]

3. Albayram S, Baş A, Ozer H, Dikici S, Gulertan SY, Yuksel A. Spontaneous intracranial hypotension syndrome in a patient with marfan syndrome and autosomal dominant polycystic kidney disease. Headache 2008;48:632-6. [CrossRef]

4. Schievink WI, Meyer FB, Atkinson JLD, Mokri B. Spontaneous spinal cerebrospinal fluid leaks and intracranial hypotension. $J$ Neurosurg 1996;84:598-605. [CrossRef]

5. Schievink WI, Ebersold MJ, Atkinson JL. Roller-coaster headache due to spinal cerebrospinal fluid leak. Lancet 1996;347:1409. [CrossRef]

6. Gabow PA. Autosomal dominant polycystic kidney disease-more than a renal disease. Am J Kidney Dis 1990;16:403-13. [CrossRef]

7. Igarashi P, Somlo S. Genetics and pathogenesis of polycystic kidney disease. J Am Soc Nephrol 2002;13:2384-98. [CrossRef]

8. Torres VE, Harris PC, Pirson Y. Autosomal dominant polycystic kidney disease. Lancet 2007;369:1287-301. [CrossRef]

9. Takagi H, Umemoto T. Matrix metalloproteinases synthesized in autosomal dominant polycystic kidney disease play a role in development of a concurrent abdominal aortic aneurysm. Med Hypotheses 2005;64:778-81. [CrossRef]

10. Hateboer N, v Dijk MA, Bogdanova N, Coto E, Saggar-Malik AK, San Millan JL, et al. Comparison of phenotypes of polycystic kidney disease types 1 and 2. European PKD1-PKD2 Study Group. Lancet 1999;353:103-7. [CrossRef]

11. Romao EA, Moyses Neto M, Teixeira SR, Muglia VF, VieiraNeto OM, Dantas M. Renal and extrarenal manifestations of autosomal dominant polycystic kidney disease. Braz J Med Biol Res 2006;39:533-8. [CrossRef]

12. Chauveau D, Fakhouri F, Grunfeld JP. Liver involvement in autosomal-dominant polycystic kidney disease: therapeutic dilemma. J Am Soc Nephrol 2000;11:1767-75.

13. Itai Y, Ebihara R, Eguchi N, Saida Y, Kurosaki Y, Minami M, et al. Hepatobiliary cysts in patients with autosomal dominant polycystic kidney disease: prevalence and CT findings. AJR Am J Roentgenol 1995;164:339-42. [CrossRef]
14. Tahvanainen E, Tahvanainen P, Kaariainen H, Höckerstedt K. Polycystic liver and kidney diseases. Ann Med 2005;37:546-55. [CrossRef]

15. Xu HW, Yu SQ, Mei CL, Li MH. Screening for intracranial aneurysm in 355 patients with autosomal-dominant polycystic kidney disease. Stroke 2011;42:204-6. [CrossRef]

16. Vanmaele R, Witbreuk M, De Broe M, Van Schil P, Lins R. Abdominal aortic aneurysm and polycystic kidneys. Nephron 1995;69:107-8. [CrossRef]

17. Bichet D, Peters D, Patel AJ, Delmas P, Honoré E. Cardiovascular polycystins: insights from autosomal dominant polycystic kidney disease and transgenic animal models. Trends Cardiovasc Med 2006;16:292-8. [CrossRef]

18. Wijdicks EF, Torres VE, Schievink WI. Chronic subdural hematoma in autosomal dominant polycystic kidney disease. $\mathrm{Am} \mathrm{J}$ Kidney Dis 2000;35:40-3. [CrossRef]

19. Holthouse D, Wong G. Chronic subdural hematoma in a 50-year-old man with polycystic kidney disease. Am J Kidney Dis 2001;38:E6. [CrossRef]

20. Schievink WI, Huston J 3rd, Torres VE, Marsh WR. Intracranial cysts in autosomal dominant polycystic kidney disease. $J \mathrm{Neu}$ rosurg 1995;83:1004-7.[CrossRef]

21. Coche E, Persu A, Cosnard G, Quoidbach A, Pirson Y. Multiple thoracic paraspinal meningeal cysts in autosomal dominant polycystic kidney disease. Am J Kidney Dis 2003;41:E8. [CrossRef]

22. Peces R, Peces C, Pérez- Dueñas V, Vega-Cabrera C, Campos I. Sacral radicular cysts in autosomal dominant polycystic kidney disease. NDT Plus 2009;2:360-1. [CrossRef]

23. Schievink WI, Palestrant D, Maya MM, Rappard G. Spontaneous spinal cerebrospinal fluid leak as a cause of coma after craniotomy for clipping of an unruptured intracranial aneurysm. $J$ Neurosurg 2009;110:521-4. [CrossRef]

24. Binder DK, Dillon WP, Fishman RA, Schmidt MJ. Intrathecal saline infusion in the treatment of obtundation associated with spontaneous intracranial hypotension: technical case report. Neurosurgery 2002;51:830-6. [CrossRef]

25. Pirson Y, Chauveau D, Torres V. Management of cerebral aneurysms in autosomal dominant polycystic kidney disease. $J \mathrm{Am}$ Soc Nephrol 2002;13:269-76.

26. Schievink WI, Parisi JE, Piepgras DG, Michels VV. Intracranial aneurysms in Marfan's syndrome: an autopsy study. Neurosurgery 1997;41:866-70. [CrossRef]

27. Schievink WI, Riedinger M, Maya MM. Frequency of incidental intracranial aneurysms in neurofibromatosis type 1. Am J Med Genet A 2005;134A:45-8. [CrossRef]

28. Schievink WI. Spontaneous spinal cerebrospinal fluid leaks and intracranial hypotension. JAMA 2006;295:2286-96. [CrossRef]

29. Schievink WI, Reimer R, Folger WN. Surgical treatment of spontaneous intracranial hypotension associated with a spinal arachnoid diverticulum. Case report. J Neurosurg 1994;80:736-9. [CrossRef]

30. Schrijver I, Schievink WI, Godfrey M, Meyer FB, Francke U. Spontaneous spinal cerebrospinal fluid leaks and minor skeletal features of Marfan syndrome: a microfibrillopathy. J Neurosurg 2002;96:483-9. [CrossRef] 